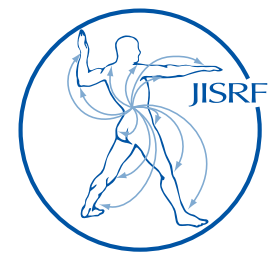

\title{
Patient Factors Affecting Surgeon Selection and the Decision to Delay Total Knee Arthroplasty
}

\author{
Berend $K^{1}$, Zhao $R^{2}$, Carlson $A^{3}$, Stultz $M^{4}$
}

\begin{abstract}
\end{abstract}
Background: Delaying total knee arthroplasty (TKA) carries an increased likelihood of poor rehabilitation outcomes. Reasons behind choosing to delay surgery are under investigated. This study explores potential factors related to the decision to delay a TKA procedure and preferences for post-surgical pain management.

Methods: A cross-sectional online survey was conducted among TKA candidates in the US.

Results: 6,298 persons received a screening questionnaire; 2,571 (41\%) completed screening with 680 (26\%) meeting survey eligibility criteria. 654 of 680 persons (96\%) completed surveys. 154 (24\%) respondents had delayed TKA. Interference with work and concerns about insufficient post-discharge pain management were found to be significant factors in this decision. A one unit increase in the ten point interference with work scale was associated with a $22 \%$ increase in the odds of delaying surgery (OR: 1.219; 95\%CI: 1.095-1.356). Surgical candidates concerned about experiencing pain during the first several weeks following surgery had significantly higher odds of delaying surgery (OR: 1.64, 95\% CI: 0.881-3.06). Ninety-two percent of respondents indicated they would seek surgeons who offered effective non-opiate pain management options during the first several weeks of the rehabilitation period; 66 percent indicated they would likely switch surgeons for access to a non-opioid pain management approach.

Conclusions: Delaying a TKA is significantly influenced by concerns about interference with work and experiencing an extended period of post-surgical pain during a potentially prolonged recovery period. Access to postoperative pain management methods that reduce or eliminate opioid use during post-discharge rehabilitation and recovery is an important factor in the selection of a joint replacement surgeon.

Keywords: knee arthroplasty; TKA ;surgical delay; post-operative pain management; non-opiate; surgeon choice Level of Evidence: AAOS Therapeutic Level V

1 Keith Berend, MD

Joint Implant Surgeons, Inc., 7277 Smith’s Mill Road, Suite 200, New Albany, Ohio 43054 USA

2 Ruizhi Zhao

Graduate Studies in Social and Administrative Pharmacy, University of Minnesota,

7-159 Weaver-Densford Hall, 308 Harvard St. SE, Minneapolis, MN 55455 USA

3 Angeline Carlson, $\mathrm{BS}, \mathrm{RPh}, \mathrm{PhD}$

Data Intelligence Consultants, LLC, P.O. Box 44993 Eden Prairie, MN 55344 USA

4 Mark Stultz, PT, MS

SPR Therapeutics, LLC, 22901 Millcreek Blvd, Suite 110, Cleveland, OH 44122 USA

(Direct reprint requests to Mark Stultz, mstultz@sprtherapeutics.com)
(C) 2017 Berend, Zhao, Carlson, Stultz. All rights reserved. Authors retain copyright and grant the journal right of first publication with the work. Reconstructive Review is an open access publication and follows the Creative Commons Attribution-NonCommercial CC BY-NC. This license allows anyone to download works, build upon the material, and share them with others for non-commercial purposes as long as they credit the senior author, Reconstructive Review, and the Joint Implant Surgery \& Research Foundation (JISRF). An example credit would be: "Courtesy of (senior author's name), Reconstructive Review, JISRF, Chagrin Falls, Ohio”. 


\section{Introduction}

Total knee arthroplasty (TKA) has been recognized as effective in the treatment of disabling pain caused by severe osteoarthritis (OA) of the knee with significant improvement in patients' quality of life [1]. Knee-replacement surgery is an increasingly common procedure--by 2030 the U.S. demand for primary TKA is projected to grow to 3.5-million [2]. The fastest growth is projected among patients $45-54$ years: from 59,000 procedures in 2006 to over 994,000 by 2030 []] .

Deferring surgery decreases the quality of patient outcomes. Postponement can lead to contralateral knee joint and other skeletal damage; weakened or lost function in muscles and ligaments; and greater difficulty or an inability to engage in normal daily activities (e.g., walking, driving, and bathing) $[4,5]$. The result is an increased likelihood of poor rehabilitation outcomes, further reduced quality of life and a negative impact on emotional well-being [6]. The earlier TKA surgery is performed, the higher the success rate and better the ultimate knee functioning []․ In addition, following failed conservative treatmentand prior to a delayed surgical intervention-individuals continue experiencing debilitating pain, reduced quality of life, and significant financial burden []].

Pain following total knee arthroplasty can be severe and opioids are commonly provided to manage postoperative pain. Even as far as one month following TKA, 56\% of patients continue taking opioids and $78 \%$ continue to complain of moderate to severe pain during ambulation [7]. Among five different surgical procedures (thoracotomy, total knee replacement, total hip replacement, radical mastectomy, lumpectomy) evaluated by Carroll and colleagues TKA patients reported the highest median days to opiate cessation: 47 days post-surgery, with $6 \%$ of opioid naive patients continuing to require these analgesics for over 5 months []. A large percentage $(31 \%$ - $84 \%)$ of those seeking treatment for opioid addiction report that their abuse ensued following a legitimate prescription from a physician $[\underline{9}, \underline{10}, \underline{11}, \underline{12}]$. Finally, patients receiving opioids rather than NSAIDs or Cox-2 inhibitors for chronic non-cancer pain are at a markedly increased risk for falls, cardiovascular events and all-cause mortality [13].

Despite the increasing number of appropriate candidates for TKA, patient acceptance of a surgery recommendation is low. The majority of OA patients ultimately refuse arthroplasty [] $]$, choosing instead to spend an average of 20 years with continuing pain []]; for young osteoarthritis patients the prospect of continuing pain is 40 or more years [] $]$.

TKA candidates may choose to delay surgery for a va- riety of reasons. Clinical literature has identified sex and race/ethnicity differences in health beliefs and values that appear to influence patients' decisions about joint replacement surgery $[14,15]$. Among health beliefs perceptions about pain and concern for interference with activities may be of particular importance. Other identified reasons include ineffectiveness of conservative measures, the perceived lack of safe and effective minimally-invasive surgical options, and concerns that the alternative treatment involves major and irreversible arthroplasty surgery []․

This study explores patients' perspectives and factors related to the decision to delay a TKA procedure. Surgical candidates suffering from knee osteoarthritis within the United States were surveyed to explore patient perspectives and factors related to the decision to delay surgery.

\section{Materials and Methods}

\section{Participants and setting}

A cross-sectional survey of individuals aged $\geq 55$ years who were considering a TKA procedure was conducted using an online survey service [16]. Eligible individuals were asked to complete a study-specific survey. Respondents completing the survey were able to direct 50 cents to the charity of their choice from a pre-selected list. Survey questions were presented in sequential order without the ability to return to a previous question to alter a response. This study was determined to be exempt from IRB review [17].

\section{Measures}

Demographic Information: Respondent data provided by the survey service included age, gender, annual household income, and education. Age was collected as both a continuous and categorical variable $(<18 ; 18-29 ; 30$ 44; 45-60; and >60). Household income was collected as a categorical variable ( $\$ 0-\$ 24,999 ; \$ 25,000-\$ 49,999$; $\$ 50,000-\$ 99,999 ;$; $100,000-\$ 149,999$; and $>\$ 150,000)$ as was education ("less than high school"; "high school degree"; "some college or associate degree"; "bachelor degree"; and "graduate degree").

Outcome Variables: The primary outcome defined for the study was the decision to delay total knee replacement surgery based on response to the question: "How likely is it that you may have delayed knee replacement surgery due to concerns that pain and/or the side effects of narcotic pain medications may extend your recovery and rehabilitation?" Responses were dichotomized: "Very likely" or "Likely" responses were considered to have delayed total knee replacement surgery; "Unlikely" or "Very unlikely" 
responses were considered not to have delayed total knee replacement surgery.

An additional outcome, years considering knee replacement surgery, was based on response to the question "For how many years have you been considering knee replacement surgery?" Responses were dichotomized: $\geq 2$ years and $<2$ years.

Independent Variables: In addition to demographic information other independent variables included measures related to pain, pain management for TKA surgery and respondent perception of new pain management strategies.

The Brief Pain Inventory [18], a widely used pain assessment tool in clinical settings, was used to assess two aspects of pain - pain severity in the previous 24 hours and interference with every day life. The Brief Pain Inventory (BPI) adopts a scale of 0 to 10 for each measure. For pain severity $0=$ complete absence of pain and $10=$ worst pain ever experienced. For interference with every day life questions (general activity, mood, walking ability, work, sleep, and enjoyment of life) $0=$ no interference and $10=$ total interference.

Several questions related to pain management and TKA surgery were included in the survey. One asked respondents to indicate their current pain management strategies. Respondents were also asked about pain concerns that most significantly impacted their decision to have knee replacement surgery (i.e., concerns about pain for the first 3 days following surgery versus concerns about pain within the first several weeks following surgery). Another question asked about their preferred postoperative pain management approach--one that offered "excellent" pain management in the hospital but would likely necessitate the use of opioid analgesics to manage pain following discharge or one that offered "adequate" pain relief in the hospital and would likely reduce or eliminate opioid medications following discharge.

Finally, respondents were asked two questions to assess their perception of a new pain management approach. "How important would it be to your choice of surgeon to know that they have been certified to use a new pain management approach that could lead to a reduction or elimination of narcotic analgesics following TKA surgery?" and "How likely are you to seek a well-qualified knee replacement surgeon who offers a new pain management approach that could lead to a reduction or minimization of narcotic analgesics following TKA surgery?"

\section{Data analysis}

Descriptive statistics are reported for age, gender, household income, and educational attainment. Continuous variables are reported as means with standard devia- tions (mean \pm s.d.); categorical variables are reported as percent of respondents.

Associations between the Brief Pain Inventory pain and interference responses and the demographic variables of age, gender, household income and educational attainment were evaluated using the Chi-Square test. For this analysis the 0-10 scales for pain and interference were classified into four categories $[\underline{19}, 20]$ : $0=$ "no pain" or "no interference"; 1-4 = "mild pain" or "mild interference"; 5-6 = "moderate pain" or "moderate interference"; 7-10 = "severe pain" or "severe interference".

BPI pain and interference responses were evaluated using Pearson's Correlation Coefficient to assess the relationship and strength of the relationship between variables. A correlation was determined to be strong if the Pearson correlation coefficient was above 0.7 ; at that level $50 \%$ of the variation in one variable is explained by its correlation with the other variable [21].

Logistic regression with stepwise model selection was employed to explore factors potentially significant in predicting the decision to delay a knee replacement surgery and the length of delay. Logistic regression predicts the odds of outcome variables from a set of independent variables [22]; stepwise model selection orders the independent variables in the regression model by a computer algorithm sequentially applying statistical tests [23] . For the logistic regression the primary and secondary study outcomes (decision to delay a TKA and length of delay, respectively) were classified into the two previously defined groups. Exploratory variables for the model included demographic variables (gender, income, education, age), concerns for pain (pain during the three days immediately post-surgery or several weeks following the surgery), and the eight BPI items for pain and interference with every day life.

All statistical analyses were completed using SAS v 9.3 (SAS Institute, Cary, NC, USA). A p-value of $<0.05$ was chosen as the threshold for statistical significance.

\section{Results}

A total of 6,298 persons were sent a screening questionnaire; 2,571 completed screening and were provided with an eligibility questionnaire; $680(26 \%)$ respondents met the eligibility criteria defined for the study. There were 654 completed surveys for a survey response rate of $96 \%$ $(654 / 680)$.

Demographic Profile: The mean age of survey respondents was $64 \pm 7$ years; $71 \%$ of the participants were 60 years or older; $65 \%$ of respondents were female (Table 1 ). 
As a group, 55\% reported educational attainment of either bachelor or graduate degree; approximately one-third (30\%) reporting household incomes of $\$ 100,000$ or more.

Pain Severity and Interference with Activities: The mean pain level was $5.6 \pm 2.2$ with a median of 6.0. Means for measures of interference with everyday life ranged from a low of 3.5 \pm 2.9 for interference with relations to a high of $6.5 \pm 2.5$ for interference with walking (Table 2). Correlations between the eight BPI items ranged from 0.397 to 0.812 suggesting a moderate to relatively strong correlation (Table 3). In the same correlation matrix, correlations of pain and interference with everyday life ranged from 0.397 to 0.574 , a moderate correlation.

Decision to Delay a TKA and Length of Delay: Among the 654 respondents 154 (24\%) responded that they had delayed TKA due to concerns that pain and/or the side effects of opioids might extend their recovery and rehabilitation. Logistic regression results indicated that only interference with work scale and age were significant predictors of delay in the stepwise model selection (Table 4). A one unit increase in the interference with work scale is associated with a $22 \%$ increase in the odds of delaying knee replacement surgery (95\% CI: 1.10-1.36). A one year increase in age is associated with a $1.3 \%$ increase in the odds of delaying knee replacement surgery, though this did not reach statistical significance (95\% CI: 0.98-1.05).

There were 352 respondents who reported they had been considering knee replacement surgery for at least two years. The factors significant in predicting this secondary outcome were also explored by logistic regression with stepwise model selection (Table 5). A one unit increase in interference with work scale is associated with a $9 \%$ increase in the odds of having considered knee replacement surgery for at least 2 years. Patients concerned about experiencing pain during the first several weeks following surgery had significantly higher odds of having considered knee replacement surgery for at least 2 years (OR: 0.59 , 95\% CI: $0.38-0.93$.

Pain Management: Among all respondents the use of opioid-containing analgesics to manage knee pain was reported by $22 \%$ of respondents; NSAID use by $62 \%$; acetaminophen by $29 \%$ and Cox- 2 inhibitors by $10 \%$. Approximately 72 percent of the respondents would accept "adequate" rather than "excellent" pain management in the first three days following the surgery if the method would also reduce or eliminate the need to take opioids for pain management during the post-discharge rehabilitation period. The majority of the respondents (74\%) were more concerned about pain they were likely to experience within the first several weeks following surgery rather than pain they were likely to experience within the first three post-
Table 1. Respondent Demographics $(n=654)$

\begin{tabular}{|c|c|c|}
\hline Measure & Frequency & Percent \\
\hline \multicolumn{3}{|l|}{ Age (mean age: $64 \pm 7)$} \\
\hline $45-60$ & 170 & 30 \\
\hline$>60$ & 413 & 71 \\
\hline \multicolumn{3}{|l|}{ Gender } \\
\hline Female & 382 & 66 \\
\hline Male & 201 & 35 \\
\hline \multicolumn{3}{|l|}{ Household income } \\
\hline$\$ 0$ - $\$ 24,999$ & 58 & 13 \\
\hline$\$ 25,000$ - \$49,999 & 90 & 20 \\
\hline$\$ 50,000$ - $\$ 99,999$ & 173 & 38 \\
\hline$\$ 100,000$ - \$149,999 & 80 & 17 \\
\hline$\$ 150,000$ and beyond & 61 & 13 \\
\hline \multicolumn{3}{|l|}{ Education } \\
\hline $\begin{array}{l}\text { Less than high school } \\
\text { degree }\end{array}$ & 2 & $<1$ \\
\hline High school degree & 37 & 6 \\
\hline $\begin{array}{l}\text { Some college or Associate } \\
\text { degree }\end{array}$ & 161 & 28 \\
\hline Bachelor degree & 171 & 20 \\
\hline Graduate degree & 208 & 36 \\
\hline
\end{tabular}

(Note: sums do not add up to $n=654$ in some categories due to missing data)

Table 2. Brief Pain Inventory

\begin{tabular}{|l|c|c|}
\hline & Mean (SD) & Median \\
\hline Pain level & $5.6(2.2)$ & 6.0 \\
\hline $\begin{array}{c}\text { Pain Interference with general } \\
\text { activity }\end{array}$ & $5.8(2.4)$ & 6.0 \\
\hline Pain Interference with mood & $4.7(2.7)$ & 5.0 \\
\hline Pain Interference with walking & $6.5(2.5)$ & 7.0 \\
\hline Pain Interference with work & $6.0(2.6)$ & 6.0 \\
\hline Pain Interference with relations & $3.5(2.9)$ & 3.0 \\
\hline Pain Interference with sleep & $4.4(2.9)$ & 4.0 \\
\hline Pain Interference with enjoyment & $5.9(2.8)$ & 6.0 \\
\hline
\end{tabular}

operative days. Overall 92 percent indicated that a new pain management approach that reduced or eliminated the use of opioid-containing pain medications would be an important factor in their choice of the surgeon they would select to perform their TKA. Even among those who had already identified a surgeon to perform their TKA, 66\% would switch to a different surgeon if they could identify another who would offer a pain management approach that reduced or eliminated opioids during the post-discharge rehabilitation and recovery period. 
Table 3. Pain Measures Correlation

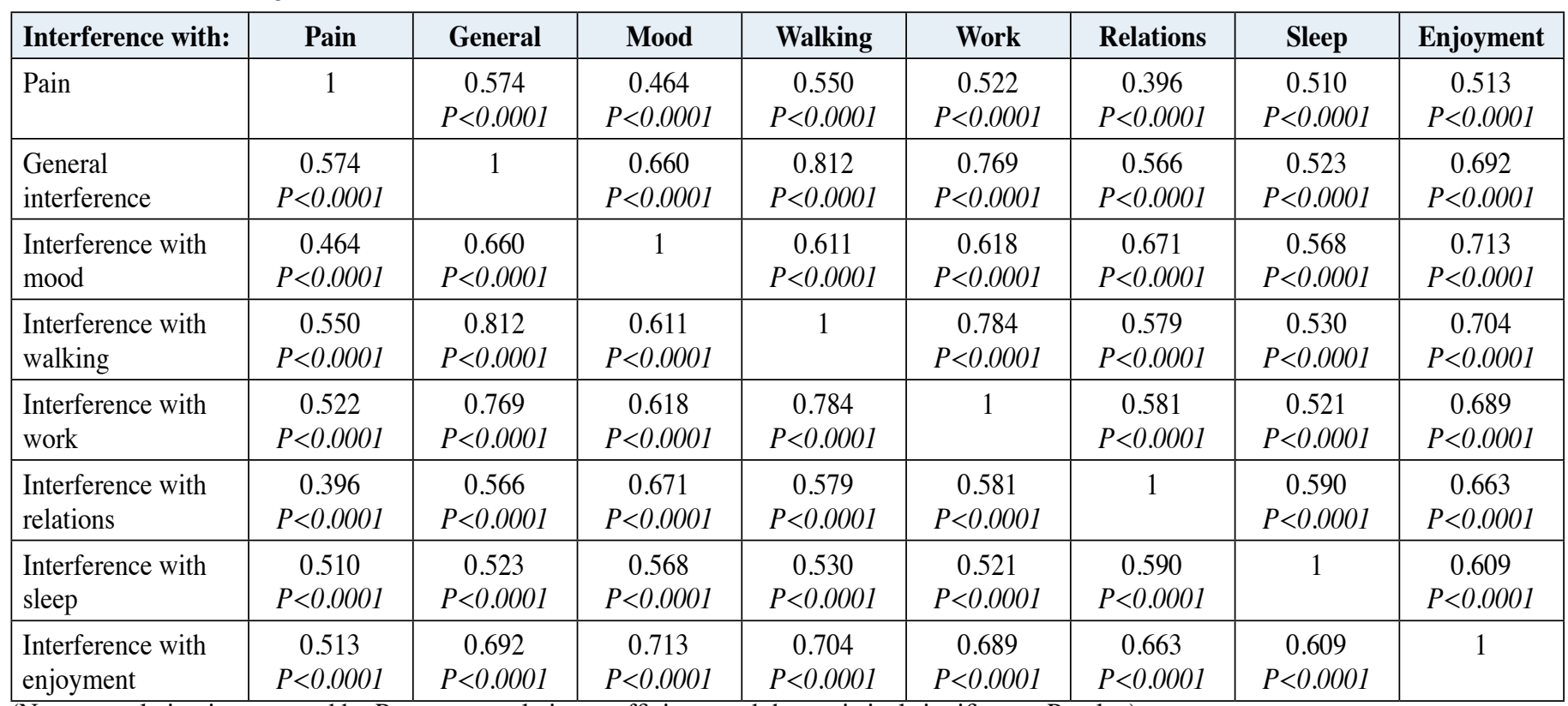

(Note: correlation is presented by Pearson correlation coefficients and the statistical significance $\mathrm{P}$-value)

Table 4. Summary of logistic regression analysis for decision of having delayed knee replacement surgery

\begin{tabular}{|l|c|c|c|}
\hline Effect & $\begin{array}{c}\text { Odds Ratio } \\
\text { Estimate }\end{array}$ & \multicolumn{2}{|c|}{$\begin{array}{c}\text { 95\% Confidence } \\
\text { Interval }\end{array}$} \\
\hline Female vs. Male & 0.985 & 0.564 & 1.722 \\
\hline $\begin{array}{l}\text { Income level (High vs. } \\
\text { Low) }\end{array}$ & 0.930 & 0.530 & 1.634 \\
\hline $\begin{array}{l}\text { Education level (High } \\
\text { vs. Low) }\end{array}$ & 1.240 & 0.711 & 2.162 \\
\hline Age & 1.013 & 0.977 & 1.051 \\
\hline $\begin{array}{l}\text { Interference with work } \\
\text { scale }\end{array}$ & 1.219 & 1.095 & 1.356 \\
\hline $\begin{array}{l}\text { Concerns for pain (3 } \\
\text { days vs. several weeks } \\
\text { following the surgery) }\end{array}$ & 0.610 & 0.327 & 1.135 \\
\hline
\end{tabular}

\section{Discussion}

This study provides strong evidence that the decision to delay a TKA is significantly influenced by surgical candidates' concerns about interference with work and experiencing pain for several weeks following TKA. In addition, access to postoperative pain management methods that reduce or eliminate opioid use is an important factor in the selection of a joint replacement surgeon. Considering that over 800,000 TKAs are performed within the United States annually, and that delaying this procedure carries an increased likelihood of poor rehabilitation outcomes, the implications of the results are significant.

Patient concern for interference with work is an important finding: a one unit increase in the interference with
Table 5. Summary of logistic regression analysis for having been considering knee replacement surgery at least 2 years or longer

\begin{tabular}{|l|c|c|c|c|}
\hline & $\begin{array}{c}\text { Odds } \\
\text { Ratio } \\
\text { Estimate }\end{array}$ & \multicolumn{2}{|c|}{$\begin{array}{c}\text { 95\% } \\
\text { Confidence } \\
\text { Interval }\end{array}$} & p value \\
\hline Female vs. Male & 1.005 & 0.655 & 1.543 & 0.9822 \\
\hline $\begin{array}{l}\text { Income level (High vs. } \\
\text { Low) }\end{array}$ & 0.716 & 0.454 & 1.128 & 0.1498 \\
\hline $\begin{array}{l}\text { Education level (High vs. } \\
\text { Low) }\end{array}$ & 1.405 & 0.901 & 2.191 & 0.1335 \\
\hline Age & 1.026 & 0.996 & 1.057 & 0.085 \\
\hline Interference with work scale & 1.086 & 1.001 & 1.179 & 0.0465 \\
\hline $\begin{array}{l}\text { Concerns for pain (three } \\
\text { days vs. several weeks } \\
\text { following the surgery) }\end{array}$ & 0.593 & 0.379 & 0.929 & 0.0224 \\
\hline
\end{tabular}

work scale was associated with a $22 \%$ increase in the odds of delaying TKA. Interference with work was the BPI item with one of the highest mean scores (6.0), and reflects a level of moderate interference. Taken together these results suggest that further investigation of the underlying factors associated with this concern is warranted. The importance of work may be related to income and education levels. It could also be related to perceived and known limitations of currently available knee replacement implants. While there have been numerous improvements in commercially available knee replacement implants, the biomechanics of the knee are not completely replicated by contemporary knee replacements, especially in regards to kneeling and twisting [24].

Previously-published studies have reflected this study's 
finding that patients who expressed concern about experiencing pain during the first several weeks following surgery also had significantly higher odds of delaying surgery. Chan and colleagues reported that patients who expressed concern about experiencing pain (first several weeks following surgery) also had significantly higher odds of delaying surgery [25]. TKA is major surgery and pain during the early days of recovery can be severe. Experiencing post-surgical pain has serious implications for post-surgery sequelae including delayed mobilization, greater risk of developing venous thrombosis, coronary ischemia, poor wound healing, longer length of hospital stay, and unnecessary psychological distress, all of which affect patient satisfaction with the surgery $[\underline{1}, \underline{25}]$. The failure to adequately relieve pain is also highly correlated with patient dissatisfaction [26].

The oral analgesics commonly being reported by respondents - primarily opioids combined with NSAIDs or acetaminophen - are not without concerns. Two concerns of particular importance are their use over an extended period and for elderly patients $[\underline{27}, \underline{28}]$. Chronic opioid use leads to the development of tolerance and hyperalgesia [27], has the potential to worsen outcomes in musculoskeletal conditions $[\underline{27}, 29]$ and, in the elderly can lead to delirium and agitation [28]. Chronic use of NSAIDs and acetaminophen both have serious safety concerns-gastric bleeding and liver toxicity, respectively $[\underline{27}, \underline{30}]$.

Pain management options that avoid opioid use are not only viewed as desirable by patients $-92 \%$ of respondents felt that a new pain management approach that reduced or eliminated the use of opioid-containing pain medications was an important factor in their choice of surgeons for TKA; this is consistent with current guidance from the US Food and Drug Administration and health professional societies, each group having expressed concerns about the current use of opioid containing analgesics. Decreasing dependence on opioid analgesics could also reduce surgical candidates' hesitation to proceeding with surgery, and thereby improve the ultimate surgical outcome for millions of individuals.

Finally, given TKA candidate concerns about post-discharge pain management that extends into the rehabilitation phase of recovery, it appears increasingly important to put mechanisms in place to measure and report patient satisfaction not only in regard to how pain is managed during their in-hospital experience, but also in regard to their experience post-discharge. TKA candidates in the valley of decision may be encouraged to learn that pain can be effectively managed during the post-discharge period and therefore be more likely to advance to surgery with less apprehension or delay.

\section{Limitations}

There are several limitations to note. This study was a cross-sectional, observational study. Only associations and not causal relationships may be concluded.

Second, though the validity of the Brief Pain Inventory has been established by various studies in assessing cancer or other chronic pains, the validity and reliability of the Brief Pain Inventory in assessing knee pain has not been thoroughly investigated.

Respondents to this study represented well-educated, reasonably middle to high income, American patients who had seriously considered TKA surgery. They may not reflect the perceptions of all TKA surgery candidates.

Finally, the survey invitation, the eligibility process and the survey were administered electronically by an on-line survey service to those who have agreed to participate in SurveyMonkey surveys. This also limits generalizability to the larger population of TKA surgery candidates.

\section{Conclusion}

This study suggests that concern about postoperative pain and its interference with work for the first several weeks following discharge is the main driving factor for delaying TKA. There is also significant interest in pain management approaches that reduce or eliminate the need for opioid-containing analgesics among those considering TKA and a willingness by them to seek out a surgeon offering a pain management approach that can accomplish this objective. Surgeons and facilities who adopt effective pain management approaches that minimize opioid use and who report the patient satisfaction associated with these approaches when used during the post-discharge period may benefit from the apparently strong aversion of TKA candidates to this class of analgesics.

\section{Disclosure}

One or more of the authors have disclosed information that may present potential for conflict of interest with this work. For full disclosures refer to last page of this journal.

\section{References}

1. Carr AJ, Robertsson O, Graves S, Price AJ, Arden NK, Judge A, Beard DJ. Knee replacement. 2012. Lancet 379: 1331-1340.

2. Kurtz SM, Ong KL, Lau E, Bozic KJ. Impact of the economic downturn on total joint replacement demand in the United States: Updated projections to 2021. 2014 Journal of Bone and Joint Surgery 96-A (8): 624-630.

3. Kurtz SM, Lau E, Ong K, Zhao K, Kelly M, Bozic KJ. Future young patient demand for primary and revision joint replacement: National projections from 2010 to 2030. 2009. Clinical Orthopedic Related Research 467: 2606-2612.

4. Hassett G, Hart DJ, Doyle DV, March L, Spector TD. 2006. The relation between progressive osteoarthritis of the knee and long term progression of osteoarthritis of the hand, hip, and lumbar spine. Ann Rheum Dis 65:623-628 
5. Arendt EA, Miller LE, Block JE. Early knee osteoarthritis management should first address mechanical joint overload. 2014. Orthopedic Reviews 6: 5188.

6. London NJ, Miller LE, Block JE. Clinical and economic consequences of the treatment gap in knee osteoarthritis management. 2011. Medical Hypotheses 76: 887-892.

7. Andersen LO, Gaarn-Larsen L, Kristensen BB, Husted H, Otte KS. Subacute pain and function after fast-track hip and knee arthroplasty. 2009. Anaesthesia 64: 508-513.

8. Carroll I, Barelka P, Wang CKM, Wang BM, Gillespie MJ, McCue R, Younger JW, Trafton J, Humphreys K, Goodman SB, Dirbas F, Whyte RI, Donington JS, Cannon WB, Mackey SC. 2012. A pilot cohort study of the determinants of longitudinal opioid use after surgery. Anesthesia and Analgesia 115 (3): 694-702.

9. National Institutes of Health Consensus Panel. NIH consensus statement on total knee replacement December 8-10, 2003. Journal of Bone and Joint Surgery 86-A (6): 1328-1335.

10. Passik SD, Hays L, Eisner N, Kirsh KL. Psychiatric and pain characteristics of prescription drug abusers entering drug rehabilitation. 2006. J Pain Palliat Care Pharmacother 20:5-13

11. Potter JS, Hennessy G, Borrow JA, Greenfield SF, Weiss RD. Substance use histories in patients seeking treatment for controlled-release oxycodone dependence. 2004. Drug Alcohol Depend 76:213-215.

12. Hays L, Kirsh KL, Passik SD. Seeking drug treatment for OxyContin abuse: a chart review of consecutive admissions to a substance abuse treatment facility in Kentucky. 2003. J Natl Compr Canc Netw 1:423-428.

13. Solomon DH, Rassen JA, Glynn RJ, Lee J, Levin R, Schneeweiss S. The Comparative Safety of Analgesics in Older Adults With Arthritis Arch Intern Med. 2010;170 (22):1968-1978.

14. Ibrahim SA, Siminoff L, Burant CJ, Kwoh CK. 2002. Understanding ethnic differences in the utilization of joint replacement for osteoarthritis: the role of patient-level factors. Medical Care 40 (1 Suppl): 44-51.

15. Suarez-Almazor ME, Soucheck J, Kelly A, O’Malley KM, Byrne MM, Richardson MM, et al. Ethnic variation in knee replacement: patient preferences or uninformed disparity? 2005. Arch Intern Medicine 165:1-8

16. SurveyMonkey ${ }^{\circledR}$. https://www.surveymonkey.com/mp/audience/our-survey-respondents/
17. Ilfeld BM. Informed consent for medical research: An ethical imperative. 2006. Reg Anesth Pain Med 31: 353-7.

18. Cleeland CS, Ryan KM. Pain assessment: global use of the Brief Pain Inventory. 1994. Ann Acad Med Singapore 23 (2): 129-138.

19. Kapstad H, Hanestad BR, Langeland N, Rustoen T, Stavem K. Cutpoints for mild, moderate and severe pain in patients with osteoarthritis of the hip or knee ready for joint replacement surgery. 2008. BMC Musculoskeletal Disorders 9:55 doi:10.1186/1471-2474-9-55

20. Jensen MP, Smith DG, Ehde DM, Robinsin LR. Pain site and the effects of amputation pain: further clarification of the meaning of mild, moderate and severe pain. 2001. Pain 91: 317-322.

21. Pearson K, Heron D. On theories of association. 1913. Biometrika 9(1/2): 159315.

22. Cox, DR. The regression analysis of binary sequences. 1958. Journal of the Royal Statistical Society. Series B (Methodological): 215-242.

23. SAS Institute. (2012). SAS/STAT 12.1 User's Guide Survival Analysis (book Excerpt). SAS Institute Incorporated.

24. Scott CEH, Howie CR, MacDonald D, Biant LC. Predicting dissatisfaction following total knee replacement: A prospective study of 1217 patients. 2010. Journal of Bone and Joint Surgery 92-B (9): 1253-1258.

25. Chan EY, Blyth FM, Nairn L, Fransen M. Acute postoperative pain following hospital discharge after total knee arthroplasty. 2013. Osteoarthritis and Cartilage 21: $1257-1263$.

26. Franklin PD, et al. Reduction in narcotic use after primary total knee arthroplasty and association with patient pain relief and satisfaction. J Arthroplasty. 2010; 25 (6, Supp 1): 12-16.

27. Zywiel MG, et al. Chronic opioid use prior to total knee arthroplasty. 2011. J Bone Joint Surg Am 93; 1988-93.

28. Crane JH, Suda KJ. Oxycodone induced delirium and agitation in an elderly patient following total right knee arthroplasty. 2011. Int J Clin Pharm. 33:733-736

29. Patanwala AE et al. Comparison of opioid requirements and analgesic response in opioid-tolerant versus opioid-naïve patients after total knee arthroplasty. Pharmacotherapy. 2008; 28 (12): 1453-60.

30. FDA. Available at http://www.fda.gov/forconsumers/consumerupdates/ ucm336581.htm 